deteriorating relationship" is too narrow. Firstly, there are additional important roles in the scenario: other people who can shift their own weight in the boat. Secondly, the context is of an increasingly financially constrained, centralised and authoritarian society, in which only the more exploitative aspects of individualism are fostered: a blustery gale in a choppy sea indeed.

The NHS is not composed solely of consultants and administrators; indeed it may be fruitful for a moment to cast other staff in the role of (more or less) dependent or individuated children. On this model, sibling rivalry between other professions for power, status, hegemony, etc., is being contained and acted out in the consultant versus administrator battle. Perhaps we shall see disputes in the 'lower ranks' involving clinical and administrative issues, which may then help the consultants and administrators either to pull together within the NHS, or finally separate (private practice).

The wider context, too, will also inevitably change. While financial constraints look set to tighten, it is by no means certain that the current emphasis on the economics of service delivery will continue to take precedence indefinitely over a medical notion which seeks to maximise the relief of individual suffering regardless of cost.

To add to Ian's prescription I would, in the mode of family rather than marital therapy, suggest that consultants and administrators could fruitfully get together to compare notes on the differences between the various pressures and constraints under which they respectively operate, and hope also that other staff will see fit to helpfully 'rock the boat'.

Department of Child and Family Psychiatry

Medway Health Authority, Chatham

Peter Hollis

\section{Old case notes}

DEAR SIRS

I wrote recently to a colleague at a particular clinic, asking him if I could borrow the notes of a child whom I had seen there when I was working in that clinic, whose younger brother had been referred to me.

I learnt to my consternation that a policy decision had been made by the clinic to destroy files on all patients when they reached the age of 25 years unless there were special reasons to retain them. The file I requested has, therefore, been destroyed.

I think this policy is an extremely unwise one. Many children with psychiatric problems grow up to have psychiatric problems as adults. It is of immense help to adult psychiatrists if they are able to consult the files of their patients when they were children. Furthermore, it vitiates any possibility of longitudinal research being done on these patients. Although the present staff of the clinic may not wish to do research, I think consideration should be given to enable those who come after to undertake this work. For example, a valuable piece of research has been done by Dr Zeitlin, ${ }^{1}$ who has linked up the patients seen as children at the Maudsley with their attendance as adults at the Maudsley and has furthered our understanding of the history of psychiatric disorder.

I understand that for reasons of space such a decision was made, but surely alternatives could be considered, such as micro-filming, rather than a wholesale destruction of vital and important clinical material.

\section{ReFERENCE}

'Zertun, H. (1986) The Natural History of Psychiatric Disorder in Children. Maudsley Monograph No. 29. London: Oxford University Press.

\section{DeAR SIRS}

I have been sent a copy of the letter complaining about our policy to destroy the old files of our patients (after they are 25) unless there are special reasons to retain them. In that letter there is a sentence: 'Although the present staff of the clinic may not wish to do research..... This is offensive, and, as such, unacceptable; maybe we are interested in other kinds of research.

Also, her consternation would have been less if she had known that a circular was sent by the Department of Health and Social Security to Regional Health AuthoritiesHC(80)7 May 1980-paragraph 5b-recommending a minimum retention period of the records for children and young people until the patient's 25 th birthday or eight years after the last entry if longer. It is what we do and, I suspect, many other agencies. The reason is the obvious one, the need for space.

However, I cannot disagree with the fact that sometimes it could be useful to have access to old files. But the alternatives suggested, like micro-filming, can be extremely expensive, and we must wonder if, in a time of expenditure cuts, a better use could not be found for the required amount of money.

(Names and addresses supplied)

\section{The dilemma of adolescent psychiatrists}

\section{DeAr SIRS}

My colleague, Tony Harbott, has v.ritten (Bulletin, January 1987, 11, 25)-perhaps more in sorrow than in anger-to reproach me for my views on the selection of disturbed adolescents for treatment (Cut Price Adolescent Units That Meet All Needs and None? Bulletin, September 1986, 10, 231-232).

The point of my paper was to emphasise the dilemma faced by all adolescent psychiatrists-if it is accepted that it is unreasonable to treat all categories in one unit, who should be excluded and what are the alternatives? In the past, most of us were taught that the treatment of conduct disorders, particularly those exhibiting personality disorder, is not really a medical responsibility, and that as a group they are not sufficiently responsive to treatment to 